\title{
BIODIGESTOR PARA O GÁS DO LIXO ORGÂNICO
}

\author{
BIODIGESTOR FOR ORGANIC WASTE GAS
}

ISSN: 1984-3151

\section{Carla Miranda Ferreira*1; Carla Barbosa Fernandes ${ }^{1}$; Aline Vieira da Silva e Souza ${ }^{1}$; Cibelly Caroliny Santos Melo ${ }^{1}$; Jefferson Santos Sales ${ }^{1}$; Marcelo Lorenzo Frade ${ }^{1}$; Marcus Vinicius Machado ${ }^{1}$; Matheus Costa Frade ${ }^{1}$; Natashua Lauar Gomes ${ }^{1}$; Pedro Henrique de Andrade Costa ${ }^{1}$; Rodrigo de Almeida Moraes ${ }^{1}$; Thales Gonçalves Estrella ${ }^{1}$; Miriam Cristina Pontello Barbosa Lima ${ }^{2}$ (Orientadora)}

\footnotetext{
1 Alunos de Graduação em Engenharia de Produção do Centro Universitário de Belo Horizonte - UniBH. Belo Horizonte, MG. "carlam.ferreira@yahoo.com.br.

2 Doutoranda em Geografia - Tratamento da Informação Espacial. PUC Minas, 2011. Professora do Centro Universitário de Belo Horizonte - UniBH. Belo Horizonte, MG. miriam.pontello@gmail.com.
}

Recebido em: 22/08/2011 - Aprovado em: 28/09/2011 - Disponibilizado em: 13/10/2011

RESUMO: Este artigo tem como objetivo apresentar uma alternativa de reutilização do gás produzido pelo lixo, por meio da construção de um biodigestor, visando a preservação do meio ambiente por meio de energia renovável. $A$ energia produzida por esse sistema, obtida da decomposição do lixo orgânico, é o biogás, formado por gases, tais como o metano (CH4) e o dióxido de carbono (CO2). Esse experimento verifica a possibilidade de utilizar o gás metano como alternativa para o funcionamento de um fogão doméstico.

PALAVRAS-CHAVE: Lixo. Sustentabilidade. Biogás.

ABSTRACT: This article to present an alternative reuse os the gas produced by garbage, through the construction of a digester, with a view to preserving the environment through renewable energy. The energy produced by this system is obtained from the decomposition of organic waste is biogas, made up of gases such as methane $(\mathrm{CH} 4$ and carbon dioxide (CO2). This experiment verifies the possibility of using methane gas as an alternative to the operation of a domestic stove.

KEYWORDS: Trash. Sustainability. Biogas.

\section{INTRODUÇÃO}

No século XIX, com o desenvolvimento da tecnologia a vapor, a biomassa passou a ser primordial para a obtenção de energia mecânica com aplicação na indústria e no transporte. Com a descoberta do petróleo e gás natural, o primeiro dominou o mundo como fonte energética. Segundo Pereira (2008):
Durante os colapsos de fornecimento de petróleo que ocorreram durante a década de 1970, essa importância tornou-se evidente pela ampla utilização de artigos procedentes da biomassa como álcool, gás de madeira, biogás e óleos vegetais nos motores de combustão interna, embora não tenha sido suficiente. Os motores de combustão interna foram primeiramente testados com derivados de biomassa, sendo praticamente unânime a declaração de que os combustíveis fósseis só 
obtiveram valor por fatores econômicos como oferta e procura, nunca por questões técnicas de adequação. (PEREIRA, 2008)

No Brasil, os problemas ecológicos se evidenciaram em consequência das bruscas mudanças climáticas ocorridas nas últimas décadas, provocadas por diversos fatores. Destaca-se a emissão de gases na atmosfera, responsável pelo efeito estufa, que se tornou um grande vilão que, em excesso, causa danos irreversíveis ao planeta terra.

O desmatamento e a queima de combustíveis fósseis são também grandes responsáveis pela emissão destes gases que, liberados no meio ambiente, afetam direta e indiretamente a biodiversidade dos ecossistemas.

De acordo com o Portal Brasileiro de Energias Renováveis :

O dióxido de carbono (CO2) é responsável por mais de $80 \%$ da poluição que gera o aquecimento global. Aproximadamente 97\% do $\mathrm{CO} 2$ emitido pelos países industrializados do ocidente surgem da queima de carvão, óleo e gás usados para produzir energia. Assim, embora pesquisadores digam que as mudanças climáticas são inevitáveis, muitos governos, entidades científicas e ONGs voltadas às questões do meio ambiente acreditam que é possível reduzir o impacto das mudanças no planeta ao implementarmos fontes energéticas renováveis.A consolidação de uma nova matriz energética que não tenha como base o petróleo é essencial para que a emissão de gases causadores do efeito-estufa entre em queda. Dessa forma, a necessidade da adoção de energias limpas e renováveis em todo mundo é uma realidade. (Portal Brasileiro de Energias Renováveis,2008)

Além de serem inesgotáveis, as energias renováveis provocam uma redução de aproximadamente 38\% no desperdício da energia consumida atualmente.

Essas fontes alternativas de energia podem ser produzidas por diversos meios naturais, como o sol, através de painéis solares que transformam os raios em energias elétricas ou térmicas; o vento por meio de turbinas e moinhos; as águas pela ação da força cinética e turbina hidráulica e ainda os resíduos vegetais e animais, pelo uso dos biodigestores.
Com o intuito de proporcionar um melhor destino para o lixo orgânico, foi desenvolvido como o objetivo geral deste trabalho um biodigestor que visa transformar 0 gás produzido pelo lixo orgânico em energia para funcionar um fogão doméstico.

Como objetivos específicos têm-se:

1. contribuir com a preservação do meio ambiente, reduzindo a emissão dos gases produzidos pela exposição do lixo;

2. desenvolver um projeto alternativo para reduzir o uso de energias não renováveis;

3. contribuir com a redução de $\mathrm{CO} 2$ na atmosfera e do efeito estufa.

Com o intuito de exemplificação da necessidade de maiores investimentos em energias alternativas, podem-se citar as variações climáticas na Amazônia e os problemas nucleares no Japão. No primeiro exemplo, tem-se um estudo realizado pelo WWFBrasil e o HSBC Climate Partnership, que evidencia a vulnerabilidade climática que a produção de energia hidroelétrica causa na região norte do país. O coordenador do Programa de Mudanças Climáticas e Energia do WWF-Brasil, Carlos Rittl afirma: "As prováveis mudanças na vazão do rio Xingu, provocadas pelas alterações climáticas, colocarão em risco a viabilidade da usina de Belo Monte". (Mudanças climáticas na Amazônia podem inviabilizar Belo Monte, Alerta WWF-Brasil, Revista acrítica,2011)

Essa viabilidade é diretamente proporcional aos riscos e instabilidades climáticas e deve ser estudada de maneira mais criteriosa, principalmente no ponto de vista financeiro. Rittl diz ainda: "Os altos custos sociais e ambientais, aliados aos riscos financeiros, deveriam levar o Governo Brasileiro a uma ampla reflexão sobre a viabilidade da obra". (Mudanças Climáticas na Amazônia podem inviabilizar Belo Monte, Alerta WWFBrasil, 2011) 
Além das opiniões de Rittl as variações climáticas futuras não estão sendo incorporadas da forma devida no planejamento energético e na análise de viabilidade de projetos hidrelétricos na Amazônia Brasileira, segundo Carlos Alberto de Mattos Scaramuzza, superintendente de Conservação do WWF-Brasil. (Mudanças Climáticas na Amazônia podem inviabilizar Belo Monte, Alerta WWF-Brasil, 2011)

Diante dessas considerações percebe-se que a produção energética no Brasil apresenta falhas de planejamento quando não mapeia os riscos $\mathrm{e}$ instabilidades no clima. Porém, além de ser de extrema necessidade esse mapeamento de riscos deve-se planejar também alternativas para suprir uma possível perda energética gerada pela efetivação destes riscos, que porventura não puderem ser evitados.

O segundo exemplo aborda a mesma temática do primeiro, a variação climática, só que no âmbito de catástrofe. Tal catástrofe iniciou-se em 11 de março de 2011 com o terremoto seguido de tsunami no Japão. Segundo o primeiro-ministro japonês, Naoto Kan, foi a pior crise desde a Segunda Guerra Mundial. Disse ainda que o país atravessava a mais grave crise nuclear desde o desastre de Chernobyl, 25 anos atrás, na extinta União Soviética. (Tsunami no Japão, Revista Veja, 2011).

Tal crise oriunda do terremoto e do tsunami se agravou ainda mais após atingir a usina nuclear de Fukushima, tanto que Naoto Kan a compara com o desastre de Chernobyl. Horas depois, o primeiro ministro tentou acalmar a população dizendo que a radioatividade estava caindo. Ele ainda diz que "A prioridade do governo é evitar os danos à saúde da população". Enquanto isso, o porta-voz da Agência de Segurança Nuclear do Japão (NISA), Hidehiko Nishiyama ameniza a equiparação das tragédias ao afirmar que as emissões radioativas de Fukushima equivalem até agora a $10 \%$ das liberadas pelo reator de Chernobyl. (Tsunami no Japão, Revista Veja, 2011) Enfim, comparação procedente ou não o que importa é minimizar esses tipos de problemas envolvendo usinas nucleares como explica o professor do Departamento de Engenharia Nuclear da UFMG, Inácio Loiola Pereira Campos:

A falha na usina nuclear do Japão serve como aprendizado para que os protocolos de segurança sejam revistos a nível mundial. Esse estudo é importante para o desenvolvimento de novas formas de produção de energia. (CAMPOS, 2011).

A minimização dos problemas nucleares, independentemente de frequência e grau crítico não implica na redução de tais usinas, pois isso afetaria muito a economia mundial. A França, por exemplo, possui um percentual de $75 \%$ de energia atômica em relação a toda produção de eletricidade.

Assim, evidencia-se 0 feliz pronunciamento do professor Campos em (CAMPUS, 2011), quando ele demonstra a importância do desenvolvimento de novas formas de produção de energia.

A partir do contexto apresentado, fica evidente a necessidade de criação de novas alternativas energéticas e o controle do uso das já existentes, consumidas desordenadamente e em grande escala.

Uma alternativa já conhecida, porém pouco utilizada é a produção de biogás através do lixo orgânico, que é formado por todos os tipos de resíduos de origem vegetal ou animal, ou seja, todo lixo originário de um ser vivo. Tais matérias, ao decomporem, geram gás metano, que pode ser utilizados para a produção de energia.

As formas de utilização desse gás para obtenção de energia são variadas. Indiretamente tem-se:

- Produção de eletricidade nas formas de gaseificação e pirólise. 
- Gaseificação, que consiste na conversão da biomassa em um gás combustível, utilizado para gerar vapor e ligar turbinas. Essas, por sua vez, ligam geradores, que transformam a energia mecânica em energia elétrica.

- Pirólise: consiste no fornecimento de calor à biomassa, que através de reação química é convertida em óleo. Esse óleo pode ser queimado para a produção de energia elétrica.

- Bio-combustíveis como etanol, metanol e biodiesel.

Depois da contextualização e do levantamento das formas de obtenção de energia através de matéria orgânica, é apresentada a justificativa para a realização deste trabalho, já que poderá ocorrer:

- Economia de gases derivados do petróleo (energia não renovável);

- Possibilidade de uso do biogás com agregação de valor econômico, devido sua venda, ou ainda como forma de responsabilidade social, através de doação do biogás para famílias carentes.

- Uso dos lodos extraídos do biodigestor como fertilizante;

- Redução na emissão de metano e óxido nitroso para a atmosfera, uma vez que o biogás gerado deverá ser queimado. Vale lembrar que as lagoas abertas emitem metano e CO2 e que o gás metano contribui mais com o aquecimento global que o último.

Portanto, estudos relacionados às energias renováveis são fundamentais para o desenvolvimento humano, o que favorece a promoção da sustentabilidade ambiental, social e econômica.

\section{BIODIGESTOR}

Estudos realizados por pesquisadores do site Faz Fácil relatam que o Brasil produz cerca de 240.000 toneladas de lixo por dia, aproximadamente $5 \mathrm{~kg}$ por pessoa.

O alto nível de consumo, conforme relatado nestes estudos se refere à elevação na comercialização de produtos industrializados no Brasil nas últimas décadas. Uma forma de neutralizar a produção de lixo, gerada pelo consumo exacerbado da população, é a reciclagem, que transforma o lixo em matéria prima.

A reciclagem preserva o meio ambiente, diminuindo a poluição da água, do ar e do solo, pois transforma materiais diversos, que outrora seriam descartados, em produtos reutilizáveis. Centenas de materiais como papel, vidro, plástico e alumínio, após serem reciclados, proporcionam direta e indiretamente diversos benefícios ao meio ambiente e a economia do país. A pesquisa do site Faz Fácil cita tais benefícios ambientais:

$50 \mathrm{~kg}$ de papel reciclado evitam o corte de uma árvore de 7 anos. Cada tonelada de papel reciclado pode substituir o plantio de até $350 \mathrm{~m} 2$ de monocultura de eucalipto. Uma tonelada de papel reciclado economiza $20 \mathrm{mil}$ litros de água e 1.200 litros de óleo combustível. A reciclagem de vidro diminui a emissão de gases poluidores pelas fábricas. A reciclagem do plástico impede um enorme prejuízo ao meio ambiente, pois o material é muito resistente a radiações, calor, ar e água. A cada quilo de alumínio reciclado, $5 \mathrm{~kg}$ de bauxita (minério com que se produz o alumínio) são poupados.A reciclagem de vidro aumenta a vida útil dos aterros sanitários $e$ poupa a extração de minérios como areia barrilha, calcário, feldspato etc. (Site Faz Fácil)

A pesquisa do site Faz fácil também cita benefícios econômicos:

A reciclagem de papel economiza matériaprima (celulose). A reciclagem de $1 \mathrm{~kg}$ de vidro quebrado (cacos) gera $1 \mathrm{~kg}$ de vidro novo, economizando $1,3 \mathrm{~kg}$ de matériasprimas (minérios). A cada $10 \%$ de utilização de cacos, há uma economia de $2,9 \%$ de energia. A reciclagem de alumínio economiza $95 \%$ da energia que seria usada para produzir alumínio primário. A reciclagem de lixo orgânico, por meio da compostagem, resulta em adubo de excelente qualidade para a agricultura. Uma única latinha de alumínio reciclada economiza energia suficiente para 
manter um aparelho de TV ligado durante três horas. (Site Faz Fácil).

Dessa forma, o estudo realizado pela Faz Fácil relata os benefícios da reciclagem, demonstrando a sua extrema importância para a sustentabilidade. A conscientização da população é um dos principais fatores desencadeadores destes benefícios.

A reciclagem é obtida por meio de determinados materiais (plásticos, alumínio, papel, vidro, etc.) no tratamento do lixo urbano como matéria-prima. Após a coleta, estes materiais são transformados em novos produtos, tais como, bolsas, brinquedos, embalagens de conserva, antenas parabólicas, peças de computadores, dentre outros.(Site Faz Fácil)

A coleta seletiva, conforme a FIG. 1, é um processo para captação de materiais reaproveitáveis previamente separados na fonte geradora, que auxilia de forma eficiente e segura a reciclagem do lixo. Esta coleta pode ser realizada em escolas, prefeituras, empresas, ONGs, dentre outros.

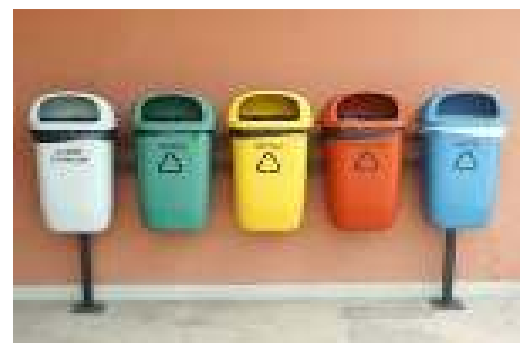

Figura 1 - Coleta Seletiva

Fonte - www.google.com.br/imagens

O aterro sanitário é utilizado como método de disposição final de resíduos sólidos, por meio de um processo de tratamento do lixo que atende a determinadas normas de controle e segurança. Normas estas que visam minimizar os impactos ambientais e os danos a saúde pública.

A maior parte dos resíduos depositados nos aterros sanitários é proveniente do lixo domiciliar, e o restante provém de resíduos de indústrias, hospitais, construções, e materiais diversos classificados como não recicláveis.
Os aterros são localizados em regiões distantes das cidades, devido ao perigo de contaminação da água, do ar e do solo.

\begin{abstract}
Antes da instalação do aterro sanitário é realizada a impermeabilização total do local que receberá os resíduos e são instaladas redes para coleta e tratamento do chorume, material que reúne todas as impurezas líquiidas e tóxicas do lixo. Os gases que emanam do aterro são captados e tratados, e a quantidade e qualidade do lixo depositado é controlada. Devido ao monitoramento constante, o aterro sanitário não contamina o solo, o lençol freático, as águas superficiais e a atmosfera. Controla ainda a proliferação de vetores de doenças e não apresenta risco de desabamentos. (Site Sua Pesquisa.com)
\end{abstract}

O lixo depositado no aterro sanitário se decompõe ao longo do tempo. Cada material tem seu tempo de decomposição. Estes dados são apresentados na Tabela 1.

Tabela 1

Tempo de Decomposição do Lixo

\begin{tabular}{|l|l|}
\hline Lixo & $\begin{array}{l}\text { Tempo de } \\
\text { decomposição }\end{array}$ \\
\hline Cascas de frutas & de 1 a 3 meses \\
\hline Papel & 03 a 06 meses \\
\hline Pano & de 6 meses a 1 ano \\
\hline Chiclete & 05 anos \\
\hline Filtro de cigarro & de 05 a 10 anos \\
\hline Tampa de garrafa & 15 anos \\
\hline Madeira pintada & 15 anos \\
\hline Nylon & mais de 30 anos \\
\hline Sacos plásticos & de 30 a 40 anos \\
\hline Lata de conserva & 100 anos \\
\hline Latas de alumínio & 200 anos \\
\hline Plástico & 450 anos \\
\hline Fralda descartável & 600 anos \\
\hline Garrafas de vidro & indeterminado \\
\hline Pneu & indeterminado \\
\hline Garrafas de plástico & tempo indeterminado \\
\hline Borracha & tempo indeterminado \\
\hline Vidro & 1 milhão de anos \\
\hline
\end{tabular}


Fonte: http://www.portalsaofrancisco.com.br/alfa/meioambiente-reciclagem/decomposicao-do-lixo.php

O estudo realizado pelo Portal de São Francisco (Tabela 1) demonstra que quanto maior o tempo de decomposição dos materiais, maior é a quantidade de lixo armazenado nos aterros. O lixo é compactado com trator e recoberto com argila para que insetos não sejam atraídos.

Ainda segundo o estudo realizado pelo Portal de São Francisco, 76\%, dos 70 milhões de quilos de lixo produzido por dia são lançados a céu aberto, 10\% em lixões controlados, $9 \%$ em aterros sanitários e apenas $2 \%$ é reciclado.

Esses dados demonstram que o tratamento e a reutilização do lixo ainda são temas pouco abordados e desenvolvidos no mundo, requerendo assim uma maior atenção, devido a grande necessidade de preservação do meio ambiente nos dias atuais.

Uma das energias renováveis é a de biomassa, já que por meio de biodigestores, a liberação de gases poluentes para a atmosfera pode ser reduzida, uma vez que são também agentes causadores do efeito estufa.

O biodigestor é um instrumento que proporciona um ambiente adequado para o reaproveitamento do lixo orgânico, pois transforma o mesmo em gases, com possibilidades de utilização em diversos setores.

A exploração dos estudos acerca das energias renováveis é um assunto importante, já que busca, cada vez mais, alternativas que possam substituir o uso das energias não renováveis utilizadas em grande escala. A utilização do biodigestor é uma alternativa, pois utiliza a matéria orgânica (biomassa) para a produção do biogás. Esse é constituído em sua maior proporção de gás metano e possibilita a geração de energia elétrica e minimiza o agravamento do efeito estufa.
Segundo o Centro Nacional de Referência em Pequenas Centrais Hidrelétricas (CERPCH), o biodigestor é um equipamento em que ocorre a transformação da biomassa em biogás. $O$ funcionamento desse equipamento consiste no armazenamento do lixo orgânico úmido ou seco. O lixo orgânico passa pelo processo de fermentação anaeróbica realizado por bactérias, transformando-se em biogás após certo período de tempo, que é impreciso, pois depende do tipo de lixo orgânico utilizado. Após todo o processo de produção do biogás, fica no biodigestor um resíduo que pode ser chamado de biofertilizante, utilizado como adubo para o solo e para o desenvolvimento das plantas.

Segundo Alcides et al (2009), a biodigestão ou fermentação anaeróbica consiste num método de reciclagem de materiais orgânicos para a formação do biogás e biofertilizante. Pode-se dividí-la em três partes distintas, sendo elas: fase da hidrólise, fase ácida e a fase metanogênica; contudo, a produção do biogás só ocorre na última fase, a da hidrólise. Nessa fase da biodigestão, as bactérias liberam no meio as chamadas enzimas extracelulares, que tem por função realizar a chamada hidrólise das partículas, que nada mais é do que a transformação, ou quebra, das moléculas maiores (polissacarídeos) em ácidos orgânicos (ácido láctico e ácido butílico), alcoóis, H2 e CO2; estas mesmas bactérias realizam ainda a fermentação de proteínas e lipídeos originando compostos semelhantes dos mesmos. $\mathrm{Na}$ fase ácida as bactérias que produzem os ácidos, transformam as moléculas de proteínas, gorduras e carboidratos em moléculas de ácidos orgânicos, etanol, amônia, hidrogênio, dióxido de carbono, dentre outros compostos. Já na última fase, a metanogênica, as bactérias denominadas metanogênicas atuam sobre $o$ hidrogênio e o dióxido de carbono e os transforma em metano (biogás). Essa é a parte mais demorada do processo, pois com o decorrer das reações químicas ocorre a formação de microbolhas de metano e 
dióxido de carbono em torno da bactéria metanogênica, isolando-a de um contato direto com a mistura. Por este motivo, é aconselhada uma agitação no biodigestor, para poder "destruir" essas microbolhas.

Deve ser levado em conta o tempo de transição destes processos, que se dá geralmente de 15 dias até a fase metanogênica, e consequentemente o início da produção do biogás. Entretanto, recomenda-se que as duas primeiras cargas sejam descartadas (os dois primeiros dias), pelo motivo de haver uma grande concentração de dióxido do carbono.

A biomassa colocada dentro do biodigestor pode estar seca ou úmida. A única diferença que existe entre esses dois tipos é a capacidade de produção, ou seja, a quantidade de gás que será produzido, pois a biomassa seca apresenta maior rendimento na produção, o que pode ser confirmado em Tiago Filho e Salomon (2007, p.12).

Segundo o Centro Nacional de Referência em Pequenas Centrais Hidrelétricas (CERPCH), existem dois tipos de biodigestores em relação ao abastecimento da biomassa: um é de produção descontínua ou batelada e o outro de produção contínua. O de produção descontínua consiste na recarga do lixo orgânico numa única vez. O recipiente é vedado para que não haja nenhum contato com oxigênio, sendo aberto só após a produção do biogás e a quantidade deste é determinada pelo medidor de gás. Já no de produção contínua, o recipiente recebe recargas de lixo orgânico durante a produção do biogás, concomitante, com a retirada do biofertilizante. No caso em estudo, utilizou-se o experimento por meio da produção contínua com o lixo orgânico.

Como exemplo dos biodigestores de alimentação contínua, que utilizam lixo orgânico ou resíduo de animais, muito utilizados no Brasil, são os modelos indiano, chinês e da marinha. Cada qual possui sua particularidade, mas em geral todos apresentam como produto final o biogás, utilizando dejetos de animais ou o lixo orgânico.

As figuras 2, 3 e 4 apresentam alguns dos vários tipos de biodigestores existentes.

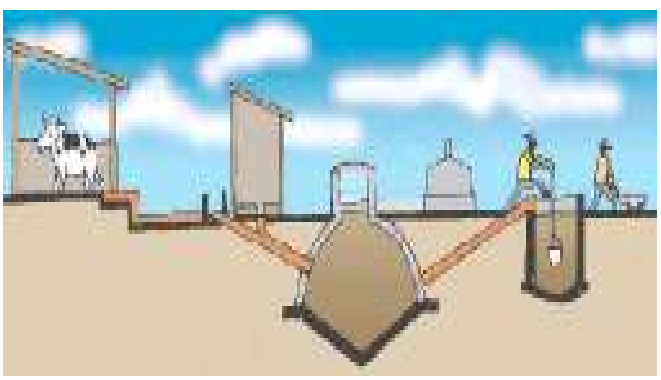

Figura 2 - Biodigestor chinês

Fonte - www.google.com.br/imagens

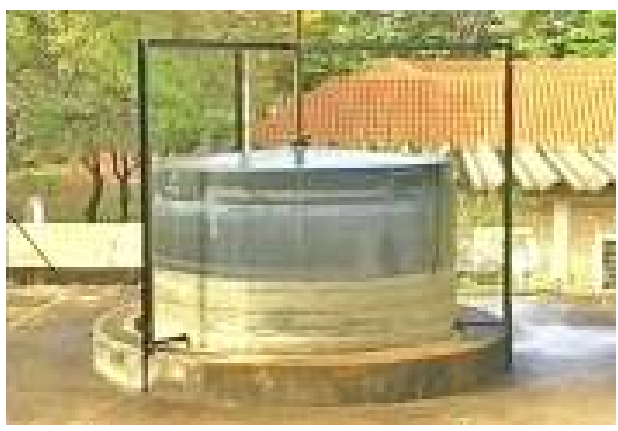

Figura 3 - Biodigestor de batelada

Fonte - www.google.com.br/imagens

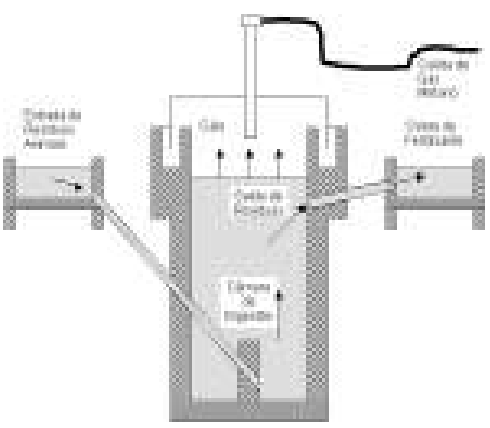

Figura 4 - Biodigestor indiano

Fonte - www.google.com.br/imagens 
A utilização do biodigestor promove uma valorização das energias ecologicamente corretas, pois dissipa o conceito da sustentabilidade, que usa a biomassa existente como uma forma de substituir o gás GLP pelo biogás.

Outro fator bastante favorável é a diminuição da emissão dos gases metano e dióxido de carbono. Contribui também para um melhor destino do lixo produzido, evitando a contaminação dos lençóis freáticos, pois a quantidade de aterros sanitários no Brasil ainda é insuficiente.

Segundo TECPAR (2002), são consideradas desvantagens do biodigestor de lixo orgânico:

- a formação de gás sulfídrico, gás tóxico com cheiro desagradável;

- a imprecisão da quantidade de biogás produzida, dependendo do tipo de resíduo, o que implica numa possível etapa de tratamento do gás obtido, conforme o uso dado ao mesmo;

- o custo extra de manutenção devido a escolha adequada do material utilizado na construção do biodigestor, pois há formação de gases corrosivos.

Segundo Carmo et al. (2005), a mistura gasosa proveniente da digestão anaeróbica do lixo orgânico constitui-se principalmente de metano $(\mathrm{CH} 4)$ : 50 a $75 \%$, dióxido de carbono (CO2): 25 a 40\%, hidrogênio (H2): 1 a $3 \%$, azoto (N2): 0,5 a 2,5\%, oxigênio (O2): 0,1 a $0,5 \%$, sulfeto de hidrogênio (H2S): 0,1 a $0,5 \%$ (um gás corrosivo e toxico, mais pesado que o ar, incolor e inflamável com limite de tolerância a exposição corresponde a $8 \mathrm{ppm}$ ou $12 \mathrm{mg} / \mathrm{m}^{3}$ ), amoniáco $\left(\mathrm{NH}^{3}\right): 0,1$ a $0,5 \%$ e monóxido de carbono (CO): 0 a $0,1 \%$ do volume de gás produzido, com variações no percentual relativo a variação de resíduos orgânicos na transformação.
O metano, principal componente do biogás, não tem cheiro, cor ou sabor, mas os outros gases presentes conferem-Ihe um ligeiro odor de alho ou de ovo podre, o que pode ser confirmado em Tiago filho e Salomon (2007, p.12).

Seixas (1980) ressalta que para a produção de biogás ser satisfatória devem ser atendidos os critérios essenciais de sustentação de vida dos microorganismos anaeróbios (bactérias), como a impermeabilidade do meio metagênico ao contato com o ar atmosférico, temperatura adequada, quantidade suficiente de nutrientes orgânicos, ausência de substâncias tóxicas aos organismos anaeróbicos e teor de água adequado.

As condições ótimas de vida para os microorganismos anaeróbios são: a) impermeabilidade ao ar, onde nenhuma das atividades biológicas dos microorganismos, inclusive seu desenvolvimento, reprodução e metabolismo, exigem oxigênio, a cuja presença são eles, de fato, muito sensíveis. A decomposição de matéria orgânica na presença de oxigênio produz dióxido de carbono (CO); na ausência de ar (oxigênio) produz metano. Se o biodigestor não estiver perfeitamente vedado a produção de biogás é inibida. b) A temperatura adequada no interior do bigestor afeta sensivelmente a produção de biogás. A atividade enzimática das bactérias depende intimamente da temperatura. Ela é fraca a $10^{\circ} \mathrm{C}$ e nula acima dos $65^{\circ} \mathrm{C}$. A faixa dos $20^{\circ} \mathrm{C}$ a $45^{\circ} \mathrm{C}$ corresponde à fase mesofílica, enquanto que entre os $50^{\circ} \mathrm{C}$ e os $65^{\circ} \mathrm{C}$, temos a fase termofílica. A opção por uma temperatura de trabalho terá de resultar do compromisso entre o volume de gás a produzir, o grau de fermentação e o tempo de retenção.

$\mathrm{Na}$ fase mesofílica, as variações de temperatura são aceitáveis desde que não sejam bruscas. O mesmo não acontece com a fase termofílica, onde as variações não são aconselháveis. Todavia, ela permite cargas mais elevadas e um tempo de retenção menor, com maiores taxas de produção de gás. c) Os principais nutrientes dos microorganismos são carbono, nitrogênio e sais orgânicos. Uma relação específica de carbono para nitrogênio deve ser mantida entre 20:1 e 30:1. A principal fonte de nitrogênio são as dejeções humanas e de outros animais, enquanto que os polímeros presentes nas culturas restantes são os principais fornecedores de carbono. d) $\mathrm{O}$ teor de água deve, normalmente, situar-se em torno de $90 \%$ do peso do conteúdo total. Tanto o excesso, quanto a falta de água são prejudiciais. $O$ teor de água varia de acordo com as diferenças apresentadas pelas matérias-primas destinadas à fermentação. e) $\mathrm{O} \mathrm{Ph}$ em meio ácido, a atividade 
enzimática das bactérias é anulada. Num meio alcalino, a fermentação produz anidrido sulfuroso e hidrogênio. A digestão pode efetuar-se entre $\circ \mathrm{pH}$ de 6,6 e 7,6. Para valores abaixo de 6,5 a acidez aumenta rapidamente e a fermentação pára. f) $A$ presença de materiais tóxicos, detergentes e outros produtos químicos devem ser evitados ao máximo, pois basta uma concentração muito baixa destes produtos para provocar a intoxicação e morte das bactérias. Qualquer elemento em solução no digestor, em excesso, pode provocar sintomas de toxidez ao meio bacteriano. A definição exata da concentração em que estes elementos passam a ser nocivos é difícil, devido à complexidade do processo. A presença de hidrocarbonetosclorofórmio, tetra cloreto de carbono e outros usados como inseticidas ou solventes industriais constituem fortes agentes tóxicos à digestão anaeróbia. A presença do íon amônio em digestores com altas taxas de produção é um significante problema. (TIAGO FILHO; SALOMON, 2007),

A viabilidade do biogás pode ser comparada com o uso das demais fontes de energia, observada na TAB. 2, a seguir.

Tabela 2

Vantagens e desvantagens do biogás

\begin{tabular}{|c|c|c|c|}
\hline $\begin{array}{l}\text { Combustível ou } \\
\text { energia potencial }\end{array}$ & Fonte & $\begin{array}{c}\text { Aspectos econômicos e } \\
\text { sociais }\end{array}$ & Impacto ambiental \\
\hline Biogás & 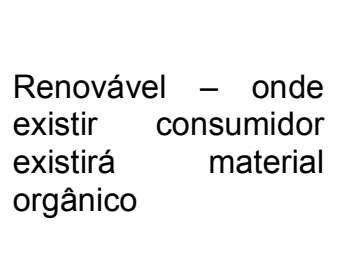 & $\begin{array}{l}\text { Lucro a longo prazo } \\
\text { encontrado em todas as } \\
\text { regiões. Redução de } \\
\text { contaminação e } \\
\text { doenças provocadas } \\
\text { pelo acúmulo de lixo e } \\
\text { esgoto a céu aberto. }\end{array}$ & $\begin{array}{l}\text { Redução de poluentes na } \\
\text { atmosfera, aterros sanitários, } \\
\text { poluição por dejetos em rios. } \\
\text { Obtenção de biofertilizantes } \\
\text { não poluentes. }\end{array}$ \\
\hline $\begin{array}{l}\text { GLP ou gás de } \\
\text { cozinha }\end{array}$ & Não renovável & $\begin{array}{l}\text { Inclui dependência } \\
\text { de fontes } \\
\text { internacionais. }\end{array}$ & $\begin{array}{l}\text { Na produção e } \\
\text { combustão, emite } \\
\text { gases poluentes e } \\
\text { tóxicos. }\end{array}$ \\
\hline $\begin{array}{l}\text { Gás natural } \\
\text { veiculado }\end{array}$ & Não renovável & $\begin{array}{l}\text { Dependência de fontes } \\
\text { internacionais }\end{array}$ & $\begin{array}{l}\text { Combustão não libera levado } \\
\text { numero de gases tóxicos, } \\
\text { ecologicamente correto. } \\
\text { Reduz desmatamentos. }\end{array}$ \\
\hline Hidrelétrica & $\begin{array}{lr}\text { Dependência } & \text { da } \\
\text { elevação do nível } \\
\text { dos rios } r \text { e } \\
\text { abundância } & \text { de } \\
\text { chuva, caso contrario } \\
\text { não existe potencial }\end{array}$ & $\begin{array}{l}\text { Construção } r \text { de } \\
\text { gigantescas usinas e } \\
\text { barragens de rios com } \\
\text { enorme potencial. }\end{array}$ & $\begin{array}{l}\text { Não libera gases tóxicos. } \\
\text { Ocorre grande interferência } \\
\text { no ecossistema no local de } \\
\text { construção das barragens. }\end{array}$ \\
\hline Petróleo & $\begin{array}{l}\text { Não renovável } \\
\text { (origem fóssil) }\end{array}$ & $\begin{array}{lr}\begin{array}{l}\text { Fontes nacionais } \\
\text { dependência }\end{array} & \text { dos } \\
\text { internacionais } & \\
\end{array}$ & $\begin{array}{l}\text { A combustão emite } \\
\text { poluentes e gases tóxicos }\end{array}$ \\
\hline Solar & Renovável & $\begin{array}{l}\text { Células solares, cada } 1 \\
\text { metro de área ocupada } \\
\text { fornece } 170 \text { watts de } \\
\text { eletricidade }\end{array}$ & Não emite poluente. \\
\hline Eólica & $\begin{array}{l}\text { Renovável existentes } \\
\text { apenas em algumas } \\
\text { regiões especificas }\end{array}$ & $\begin{array}{l}\text { Grande custo de } \\
\text { manutenção e área a } \\
\text { ocupar }\end{array}$ & $\begin{array}{l}\text { Inexistência de emissão de } \\
\text { poluentes. Turbinas podem } \\
\text { matar aves na região } \\
\text { instalada. }\end{array}$ \\
\hline
\end{tabular}


Fonte - Revista Eletrônica de Educação e Tecnologia do SENAI-SP.ISSN: 1981-8270. v.3, n.7, out. 2009

\section{BIODIGESTOR PARA O LIXO ORGÂNICO}

O biodigestor é um equipamento que tem a função de gerar biogás, através da fermentação do lixo e neste caso tem a finalidade de fazer funcionar um fogão doméstico.

Para construção do biodigestor foi utilizado solda, tambor, presilha, luva galvanizada, registro, mangueira, suporte, silicone, fita veda rosca, conforme a TAB. 3, que apresenta os materiais utilizados, com seus respectivos preços.

Tabela 3

Materiais utilizados no Biodigestor.

\begin{tabular}{|c|c|c|}
\hline Quantidade & Material & $\begin{array}{c}\text { Preço em } \\
\text { reais }\end{array}$ \\
\hline 3 & solda & 150,00 \\
\hline 2 & tambor & 100,00 \\
\hline 6 & presilha & 3,00 \\
\hline 3 & $\begin{array}{c}\text { luva } \\
\text { galvanizada }\end{array}$ & 18,00 \\
\hline 3 & registro & 75,00 \\
\hline 1 & mangueira & 10,00 \\
\hline 3 & suporte & 30,00 \\
\hline 2 & silicone & 10,00 \\
\hline 2 & fita veda rosca & 4,00 \\
\hline Total & & 400,00 \\
\hline
\end{tabular}

Foram soldados os registros nos tambores como nas figuras 5,6 e 7 .

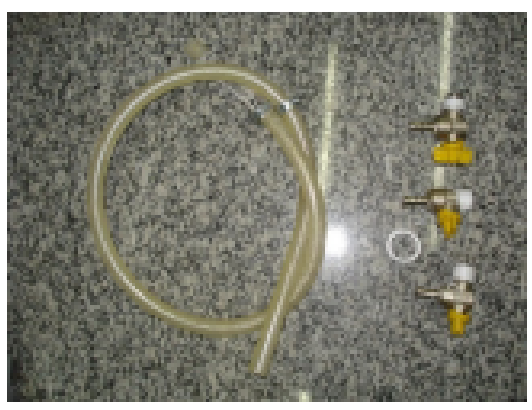

Figura 5 - Mangueira e válvulas

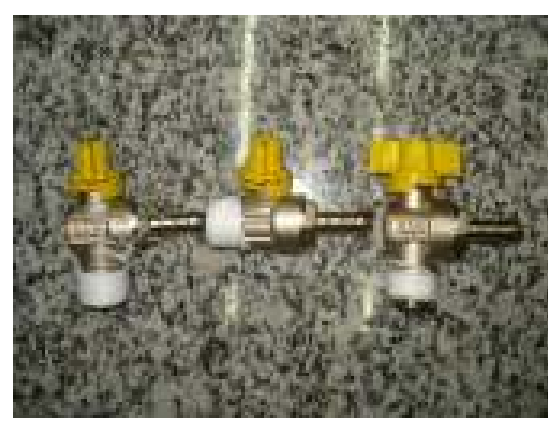

Figura 6 - Válvulas

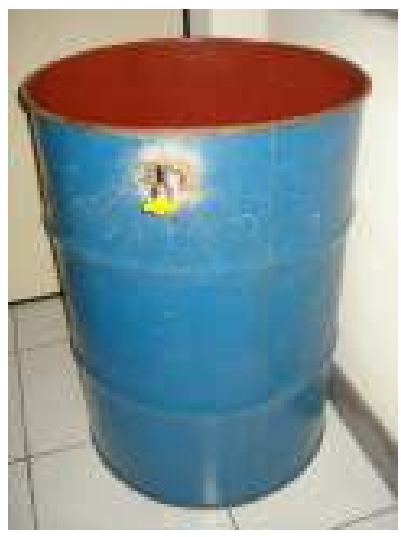

Figura 7 - Tambor

No tambor que recebe o lixo e a água foi colocado um registro e no outro que armazena o biogás foram implantados mais dois, um para a entrada do biogás e outro para conectar a mangueira ao fogão.

Logo após a implantação dos registros nos tambores, todo o lixo foi pesado em uma balança tradicional e a quantidade de água colocada na mesma proporção.

No primeiro tambor foram colocados $26 \mathrm{~kg}$ de lixo orgânico que era composto em sua maior parte por: casca de ovo; arroz, feijão; milho; carne de porco e boi; peito de peru; torresmo; casca de batata; batata cozida; chuchu; cenoura; alface; cebola; couve; pimentão; farofa; batata frita; uva; banana; mamão. Depois de colocado o lixo, foram acrescentados 26 litros de água, conforme as figuras 8,9 e 10. 


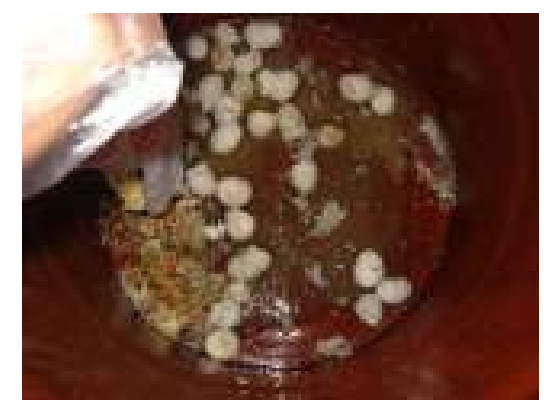

Figura 8 - Lixo orgânico utilizado

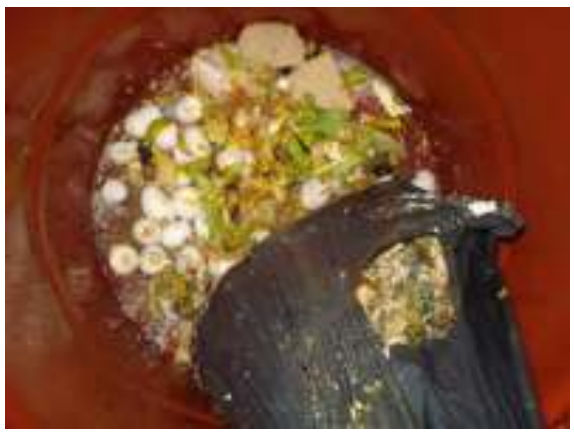

Figura 9 - Lixo orgânico utilizado

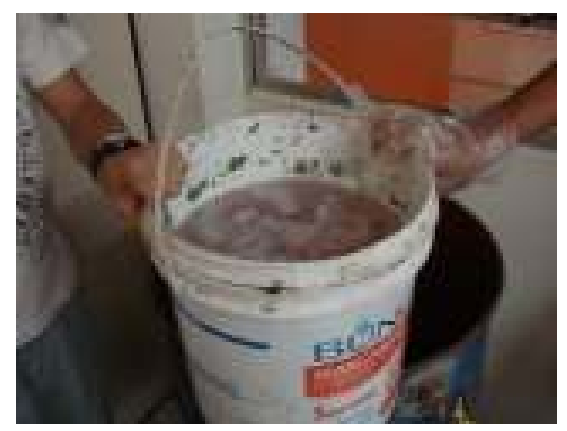

Figura 10 - Agua utilizada

Logo após fechar o tambor o registro também foi fechado e o medidor de gás foi colocado no registro do tambor, que estava com o lixo conectado ao tambor que recebe o biogás. Para evitar o vazamento de gás utilizaram-se presilhas e silicone.

Após o término da montagem do experimento, conforme a FIG. 11, abriu-se o registro do tambor com lixo e o registro do tambor, que recebe o biogás. Manteve o registro que conecta a mangueira ao fogão fechado e deixou o biodigestor produzindo biogás 30 dias.

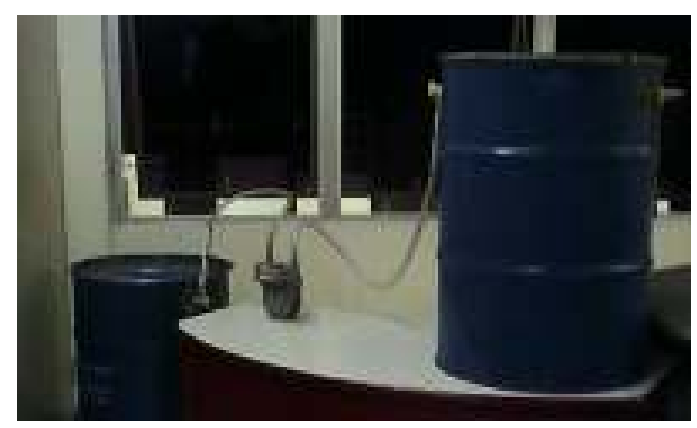

Figura 11 - Biodigestor pronto

No dia 4 de maio de 2011 foi realizado o primeiro teste no protótipo do biodigestor, que continha lixo em decomposição há 30 dias.

Foi inserido em uma das válvulas do tambor, que não continha lixo, uma mangueira que por sua vez, através de outra válvula, estava ligada a um fogão industrial de duas bocas.

Abertas todas as válvulas do sistema, foi testado o acendimento do fogão através do gás do lixo.

O teste não foi satisfatório, já que a quantidade de gás produzido não foi suficiente para o funcionamento do fogão. Uma pequena produção de gás pode ser observado no balão fixado no tambor como na FIG. 12.

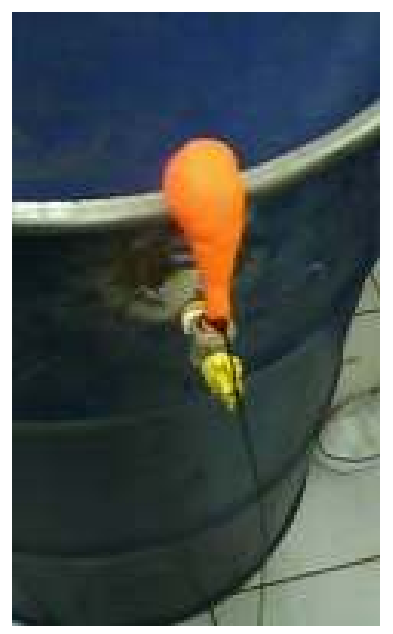

Figura 12 - O balão sendo enchendo com o biogás produzido do lixo orgânico 
Após o primeiro teste, foram feitos estudos sobre alternativas de melhorar o funcionamento do biodigestor, tais como:

- Os tambores devem estar com vácuo;

- O tempo de produção do gás deve ser superior a um ano;

- O lixo orgânico deve estar apenas úmido;

- O biodigestor deve ter uma temperatura elevada de acordo com a fase do experimento.

Tais pontos foram levantados em conformidade com Seixas (1980), que aborda os critérios essenciais de sustentação da vida dos microorganismos anaeróbicos.

Para a coleta de maiores informações práticas para construção e melhor funcionamento do biodigestor foi feita uma visita técnica na empresa Consórcio Horizonte Asja. A empresa italiana, que tem sede no Brasil, produz biogás através do lixo orgânico recolhido pela SLU (Superintendência de limpeza urbana da Prefeitura Municipal de Belo Horizonte).

A produção do biogás da empresa se difere do biodigestor apresentado neste artigo, já que o lixo orgânico é enterrado, o biogás é queimado e o restante não utilizado entra no processo de resfriamento para poder ser utilizados nos geradores que o transformam em energia elétrica. A empresa vende a energia gerada para a Cemig.

Segundo os engenheiros da Asja a presença de oxigênio em grande quantidade e a proporção de água utilizada podem ser os principais erros no biodigestor construído. Outros fatores como tempo de produção do biogás que varia de acordo com cada tipo de lixo e temperatura são fatores que influenciaram e dificultaram a produção do biogás.

\section{ConClusÃo}

Neste trabalho, descreveu-se a construção de um biodigestor, que tem a função de transformar o lixo orgânico em biogás. Pode-se observar que a produção do biogás proposta neste trabalho, através das pesquisas realizadas e aqui expostas, torna-se viável por meio do aquecimento do biodigestor, preferencialmente de forma natural, como por exemplo, o aquecimento solar auxiliado por uma lona preta. Foi verificado que a quantidade de lixo e o tempo de armazenamento para a produção do gás pode durar meses ou até anos. Sendo assim, o teste realizado no biodigestor não foi satisfatório, já que o biodigestor não possuía vácuo, temperatura elevada e a quantidade de água utilizada foi excessiva.

\section{REFERÊNCIAS}

ALCIDES et al. Relátorio do projeto integrado $I$. Centro Universitário da Fundação Educacional de Barretos- UNIFEB, set.2009. Disponível em: <http://www.ebah.com.br/content/ABAAAAa4YAL/biodi gestor>. Acesso em: 24 maio 2011.

CARMO, Eduardo M. do et al. A energia limpa da sujeira orgânica. Revista Eletrônica de Educação e Tecnologia do SENAI-SP. ISSN: 1981-8270. v.3, n.7, out. 2009.

CERPCH - CENTRO NACIONAL DE REFERÊNCIA EM PEQUENAS CENTRAIS HIDRELÉTRICAS. Fontes Renováveis: Biodigestor. Disponivel em: <http://www.cerpch.unifei.edu.br/biodigestor.php >. Acesso em: 15 mar. 2011.

ESPECIALISTA NÃO ACREDITA EM CRISE ENERGÉTICA. Hoje em dia, março 2011. Disponível em: <http://www.hojeemdia.com.br/cmlink/hoje-emdia/noticias/mundo/especialista-n-o-acredita-em-criseenergetica-1.253797>. Acesso em: 11 abr. 2011.

FAZ FÁCIL. Reciclagem. Disponível em: $<$ http://www.fazfacil.com.br/materiais/reciclagem.html> . Acesso em: 22 abr. 2011. 
MUDANÇAS CLIMÁTICAS NA AMAZÔNIA PODEM INVIABILIZAR BELO MONTE, ALERTA WWFBRASIL: Variações climáticas futuras não estariam sendo incorporadas no planejamento energético na Amazônia Brasileira. Manaus: Acrítica, abril 2011. Disponível

em:

$<$ http://acritica.uol.com.br/amazonia/Amazonia-

Amazonas-Manaus-Mudancas-Amazonia-Belo-MonteWWF-Brasil_0_458954270.html>. Acesso em: 11 abr. 2011.

PEREIRA, Margarida Maria Faria. A energia. 2008. Disponível

em:

<http://www.notapositiva.com/trab_estudantes/trab_est udantes/eductecnol/7energia.htm\#vermais>. Acesso em: 22 maio 2011.

PORTAL BRASILEIRO DE ENERGIAS RENOVÁVEIS. Disponível em: $<w w w . e n e r g i a r e n o v a v e l . o r g />$. Acesso em: 29 mar. 2011.

PORTAL SÃO FRANSCISCO. Aterro sanitário. Disponível em:

<http://www.portalsaofrancisco.com.br/alfa/meioambiente-reciclagem/aterro-sanitario.php>. Acesso em: 22 abr. 2011.
SEIXAS, Jorge et al. Construção e funcionamento de biodigestores. Brasília: EMBRAPA - DID, 1980. EMBRAPA-CPAC. Circular técnica, 4.

SUA PESQUISA. Aterro Sanitário. Disponível em: $<$ http://www.suapesquisa.com/o_que_e/aterro_sanitari o.htm>. Acesso em: 22 abr. 2011.

TECPAR - INSTITUTO DE TECNOLOGIA DO PARANÁ. Manual de Biossistemas Integrados na Suinocultura. Curitiba, Paraná - 2002. p 140.

TIAGO FILHO, Geraldo Lúcio; SALOMON, Karina Ribeiro. Série Energias Renováveis: BIOMASSA. $1^{\text {a }}$ edição. 36 p. Itajubá, 2007. Disponível em: <http://www.cerpch.unifei.edu.br/cartilhas.php >. Acesso em: 19 abril 2011.

TSUNAMI NO JAPÃO. Abril, 2011. Disponível em: <http://veja.abril.com.br/tema/tsunami-no-japao> Acesso em: 11 abr. 2011. 